\begin{tabular}{|c|c|c|}
\hline & $\begin{array}{c}\text { International Journal of Current Research in } \\
\text { Biosciences and Plant Biology }\end{array}$ \\
\hline EXCELLENT \\
PUBLISHERS
\end{tabular}

\title{
The Potency of Endophytic Fungal Isolates from Local Aromatic Rice as Plant Growth Promoting Agents
}

\author{
Syamsia $^{1} *$, Abubakar Idhan ${ }^{1}$ and Muhammad Kadir ${ }^{2}$ \\ ${ }^{1}$ Agriculture Faculty of Muhammadiyah University, Makassar, Sulawesi Selatan 90221, Indonesia \\ ${ }^{2}$ Department of Plantation Crop, Agriculture Polytechnic Pangkep, Pangkep 90655, Indonesia \\ *Corresponding author.
}

\begin{tabular}{|c|c|}
\hline Abs & Article Info \\
\hline \multirow{5}{*}{$\begin{array}{l}\text { This study aimed to obtain isolates of endophytic fungi from several local aromatic rice } \\
\text { varieties in South Sulawesi that can be used as agents of plant growth promoter. Isolation } \\
\text { of endophytic fungi carried out at the roots, stems and leaves of rice plants. Fungal } \\
\text { isolates were purified tested for its ability to produce the hormone indole- } 3 \text {-acetic acid } \\
\text { (IAA) and test the growth of rice seed. The results showed that there were } 12 \text { fungal } \\
\text { isolates were successfully purified and all of them have the ability to produce hormones } \\
\text { varied from } 0: 44 \text { to } 5: 44 \mathrm{mg} / \mathrm{l} \text {. Isolates that have the highest IAA hormone production } \\
\text { ability is isolated from the leaves Pare PLD2 Lambau. All isolates had potential as a plant }\end{array}$} & $\begin{array}{l}\text { Accepted: } 30 \text { November } 2016 \\
\text { Available Online: O6 January } 2017\end{array}$ \\
\hline & Keywords \\
\hline & Endophytic fungi \\
\hline & Indole-3-acetic acid (IAA) \\
\hline & Local aromatic rice \\
\hline
\end{tabular}

\section{Introduction}

This study aimed to obtain isolates of endophytic fungi from several local aromatic rice varieties in South Sulawesi that can be used as agents of plant growth promoter. Isolation of endophytic fungi carried out at the roots, stems and leaves of rice plants, fungi Isolates were purified tested for its ability to produce the hormone indole-3-acetic acid (IAA) and test the growth of rice seed. The results showed that there were 12 fungal isolates were successfully pure cultured and all of them have the ability to produce hormones varied from $0: 44$ to $5: 44 \mathrm{mg} / \mathrm{l}$. Isolates that have the highest IAA hormone production ability is isolated from the leaves Pare PLD2 Lambuat. All isolates had potential as a plant growth promoter. Local aromatic rice production is still very low and it has not been able to compete with the varieties from the outside as Variety released by IRRI, Celebes, Sprott Nur, Gilireng because local aromatic rice farmers cultivated for family consumption scale.

One effort that can be done to increase growth and local aromatic rice production is through the utilization of endophytic fungi. According to Moore-Landecker (1996), there are three potential beneficial for crops infected by endophytic fungus, namely: 1) increase the vegetative growth of plants; 2) the plants more tolerant to drought; and 3 ) produce a toxin that protects plants from pathogens.

Endophytic fungi are generally symbiotic mutualism with the host plant. Endophytic fungi benefit the host plants which include an increase in the growth rate, resistance to pests, disease and drought (Purwantisari and Hastuti, 2009). Colonization of endophytic fungi on host 
plants contributed to the genotype of the plant to adapt to biotic and abiotic stress conditions (Waller et al., 2005; Bae et al., 2009; Hubbard et al., 2012).

Some endophytic microbes can produce hormones that can stimulate plant growth. One of the hormones produced by the endophyte is miroba IAA or better known as auxin. Hormone auxin plays a role as a driver of growth on the meristem tissue (Spaepen et al., 2007). Auxin is one of the hormones that can stimulate plant growth by improving processes and stem cell elongation as well as cell differentiation (Nassar et al., 2005; Khaerani, 2010).

Endophytic fungus also has potential as a biological control agent and biofertilizer due to the presence of endophytic fungi are very diverse and abundant, can be found in agricultural crops and in grasses (Faeth, 2002). Some research indicates that the endophytic fungus has great benefits to plants, especially in improving the growth of plants. Endophytic fungus Aspergillus niger can enhance the growth and yield of rice and corn (Sutoyo, 2009; Saylendra, 2013).

This study was aimed to isolate and to test the ability of endophytic fungal isolates from South Sulawesi local aromatic rice for the production of IAA hormone that can stimulate the growth of the rice plant.

\section{Materials and methods}

\section{Research sites}

This research was conducted at the Laboratory of Microbiology, Faculty of Agriculture and Biotechnology Laboratories Center Research Activities -October UNHAS in May 2015. This study consisted of four stages, as detailed below.

\section{a. Isolation and purification of endophytic fungus}

Isolation of endophytic fungi was done on the leaves, stems and roots of plants. The isolation of endophytic fungi was carried out following the modified method of Rodriquez et al. (2009). Sterilization of plant parts was done gradually by immersing for 60 seconds in $70 \%$ ethanol, $3 \% \mathrm{NaOCl}$ for 60 seconds, and $70 \%$ ethanol for 30 seconds. Then rinsed four times with sterile distilled water and dried on sterile filter paper. Cut small parts of the plant were used to be grown in PDA media.

\section{b. Endophytic fungus growth test isolates on PDA media}

Endophytic fungus growth test isolates on PDA was done by growing pure endophytic fungi. Measuring the diameter of the fungal colony was done every day for 7 days.

\section{c. Production IAA hormone}

Endophytic fungal isolates were purified rejuvenated on PDA (Potato Dextrose Agar) and incubated for 7 days. Then isolates were grown in liquid medium Potato handed Broth (PDB) and supplemented with Ltryptophan $(0.1 \mathrm{~g} / \mathrm{l})$ and incubated at room temperature in a dark room and dishaker with a speed of $150 \mathrm{rpm} / \mathrm{min}$ for 7 days. Supernatant was taken after the suspension of fungi was centrifuged with a speed of $5000 \mathrm{rpm}$ for 25 minutes.

Then $1 \mathrm{ml}$ supernatant was taken and added to $1 \mathrm{ml}$ of reagent Salkowski (12 $\mathrm{g} / \mathrm{F} \mathrm{FeCl}_{3}$ in $429 \mathrm{ml} / \mathrm{l} \mathrm{H}_{2} \mathrm{SO}_{4}$ ) (Glickman and Dessaux, 1995). The mixture was stored for $24 \mathrm{hrs}$ at room temperature in dark conditions. Pink color change in the culture filtrate showed the ability to produce the hormone IAA endophytic fungal isolates. Concentration quantitatively measured by a spectrophotometer at a wavelength of $535 \mathrm{~nm}$.

\section{d. Selection of endophytic Fungus in rice seeds}

Rice seeds were surface sterilized and the seeds were subsequently germinated on pure cultures of endophytic fungal isolates whose growth has met Petri dish (approx 14 days old). If the seeds planted are not capable of germination means the fungus are pathogenic and cannot be used as an antagonist agent. Seeds that germinate on the plates were transferred into a polybag containing sterile soil, later observed for the symptoms of disease arising from endophytic fungi inoculation.

\section{Results and discussion}

\section{Isolation and purification of endophytic fungus}

Twelve endophytic fungal isolates were isolated and purified from three types of local aromatic rice, Pulu Mandoti South Sulawesi, Pulu lotong and Pare Lambau. The colony color of endophytic fungal isolates was found to be varied: white, cream, yellow, green and brown (Fig. 1). 

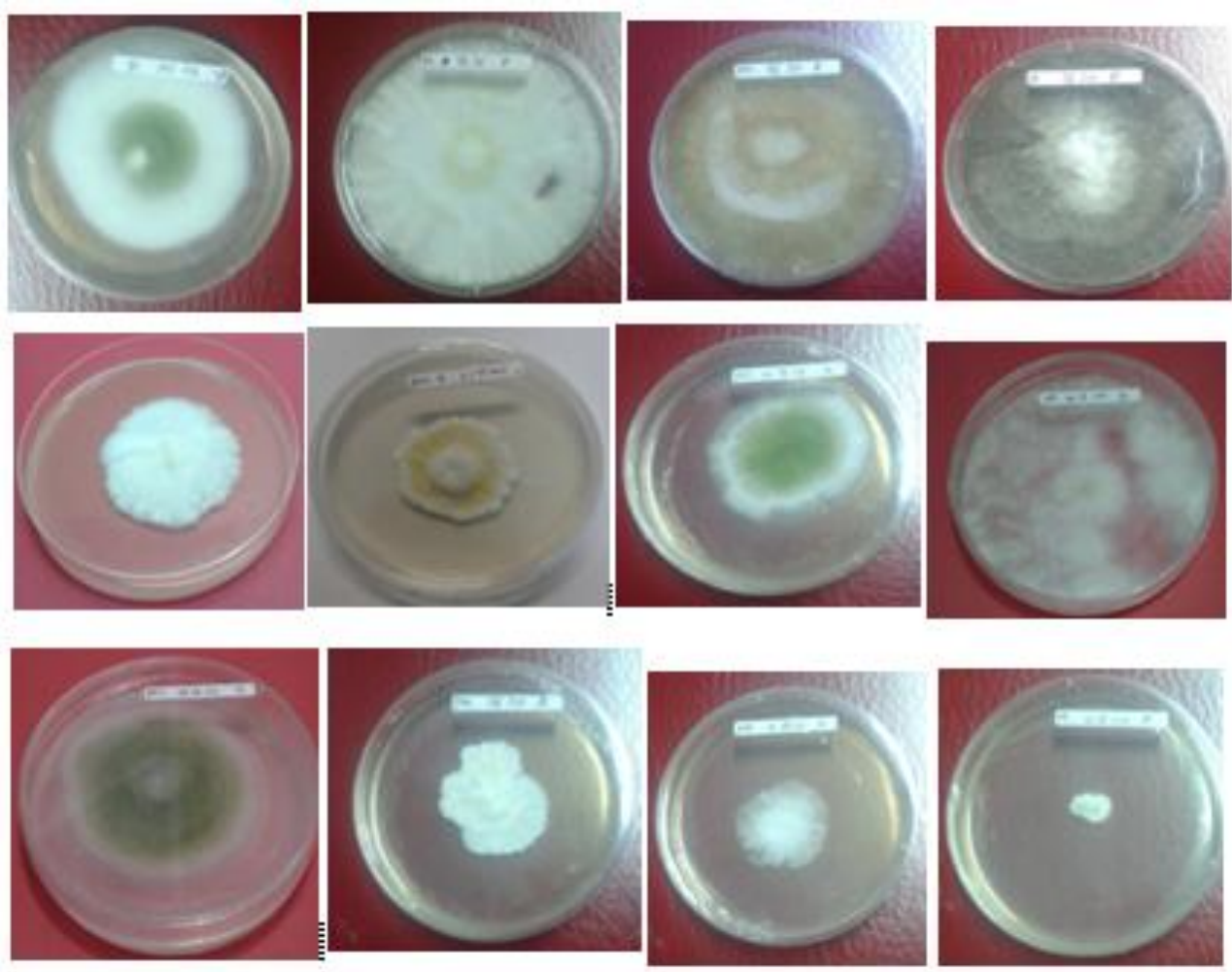

Fig. 1: Isolate endophytic fungi from three types of local aromatic rice South Sulawesi on PDA age of 7 days.

Endophytic fungal isolates colony growth on PDA showed varying results. Three isolates showed rapid growth, at the age of 4 days, the fungal colony diameter reached 3.4 to 4 $\mathrm{cm}$, and one fungal isolate showed a diameter of 4 in the growth medium which was achieved on the 7th day; three isolates showed slow growth with a diameter of 1.5-2.5 at day 7; five isolates showed very slow growth with a diameter of $0.5-1 \mathrm{~cm}$ on day 7 (Fig. 2).

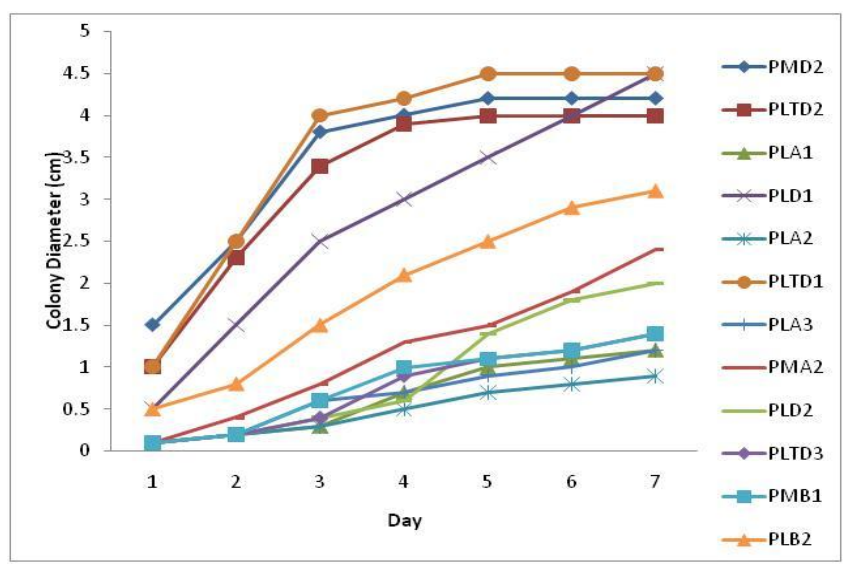

Fig. 2: Diameter Endophytic Fungi Isolates on PDA Media.

\section{Hormone production-IAA}

All isolates of endophytic fungi were cultured on medium GDP + L-Tryptophan after test, is capable of producing IAA. IAA production is indicated by a change in the color pink on filtered culture isolates of endophytic fungi after Salkowski reacted with reagent and incubated for $1 \mathrm{hr}$ at room temperature in the dark.

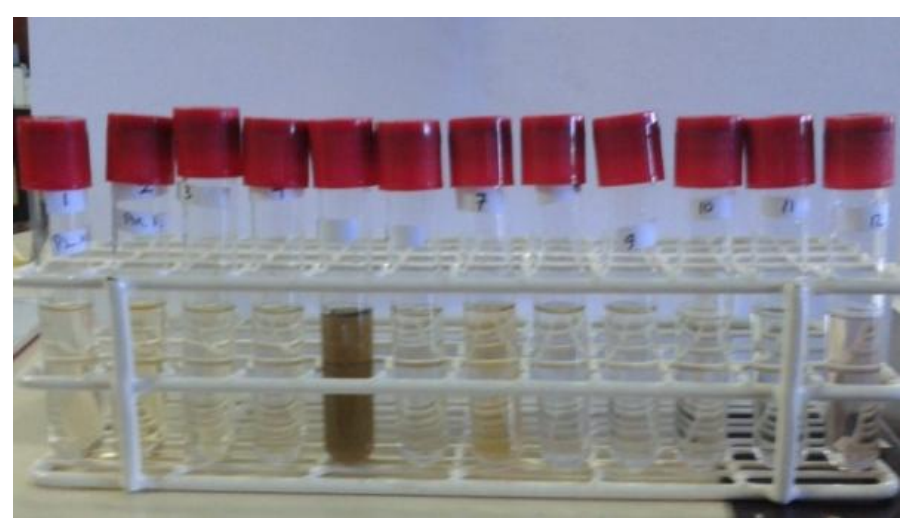

Fig. 3: Change in the culture filtrate pink color is an indicator of the ability to produce the hormone IAA.

Quantitative test results endophytic fungal isolates ability to produce the hormone IAA showed mixed results.

Isolates which has the highest ability to produce the hormone IAA were found to be the isolates from rice leaves Pare Lambau (PLD2) and the lowest was isolated from rice leaves Mandoti Pulu (Table 1). 
Table 1. Production of hormone IAA by endophytic fungus isolated from local aromatic rice.

\begin{tabular}{ll}
\hline Isolates code & Concentration of IAA $\left(\mathbf{m g l}^{\mathbf{1}}\right)$ \\
\hline PMD2 & 0.81 \\
PLTD2 & 1.41 \\
PLA1 & 2.48 \\
PLD1 & 4.88 \\
PLA2 & 3.96 \\
PLTD2 & 1.74 \\
PLA2 & 3.42 \\
PMA2 & 2.75 \\
PLD2 & $\mathbf{5 . 4 4}$ \\
PLTD3 & 2.21 \\
PMB1 & $\mathbf{0 . 4 4}$ \\
PLB2 & 1.07 \\
\hline
\end{tabular}

Based on Table 1 above, isolate endophytic fungus which has the ability to produce hormones IAA varying from $0.44-5: 44$. Similar ability of endophytic fungi in producing a hormone IAA PLD2 higher than the fungal isolates of the cacao plant root that is $0349-2794 \mu \mathrm{g} / 1$ has been reported by Iradhatullah et al. (2015).

\section{Test endophytic fungi on rice seed}

Test the growth of rice seeds in endophytic fungal isolates twelve isolates showed that they have the potential as a driver for the development of plants, because all the rice seeds were germinated to grow and showed no symptoms of the disease.

\section{Conclusion}

There were 12 endophytic fungal isolates were isolated and purified from three types of local aromatic rice varieties and all the isolates showed the ability to produce the hormone IAA which varied from 0:44 to $5: 44 \mathrm{mg} / \mathrm{l}$. The fungal isolate which has the highest production ability of the hormone IAA was found to be PLD2. All the isolates showed the potential to be used as a plant growth promoter.

\section{Conflict of interest statement}

Authors declare that they have no conflict of interest.

\section{Acknowledgement}

Authors are thankful to the Director General of Higher Education, Indonesia for funding the research activities through Research Grant Competition in 2016.

\section{References}

Bae, H., Sicher, R. C., Kim, M. S., Kim, S. H., Strem, M. D., Melnick, R. L., Bailey, B. A., 2009. The beneficial endophyte Trichoderma hamatum isolate DIS $219 \mathrm{~b}$ promotes growth and delays the onset of the drought response in Theobroma cacao. J. Exp. Bot. 60, 3279-3295.

Faeth, S. H., 2002. Are endophytic fungi defensive plant mutualists? Oikos. 98, 25-36.

Glickman, E., Dessaux, Y., 1995. A critical examination of the specificity of the Salkowski reagent for inolic compounds produced by phytopatogenic bacteria. Appl. Environ. Microbial. 61, 793-796.

Hubbard, M., Germida, J., Vujanovic, V., 2012. Fungal endophytes improve wheat seed germination under heat and drought stress. Botany. 90, 137-149.

Iradhatullah, R., Kuswinanti, T., Asrul, L., Rasyid, B., 2015 . Growth rate and indole acetic acid production of several fungal rot isolates. Int. J. Sci. Res. 4(6), 1636-1638.

Khairani, G., 2009. Isolation and ability test of entophytic bacteria producing IAA (Indole Acetic Acid) hormone from crops maize root (Zea mays L) (skripsi). Departement of Biology Faculy of Mathtematic and Natural Science North Sumatra University.

Moore-Landecker, E., 1996. Fundamental of the Fungi. $4^{\text {th }}$ Edn. Prentice-Hall, New Jersey.

Nassar, A.H., El-Tarabily, K.A., Sivasithamparam, K., 2005. Promotion of glant browth by an auxin producing isolate of the yeast Williopsis saturnus endophytic in maize roots. Biol. Fertil. Soils. 42(2), $97-108$.

Purwantisari, S., Hastuti, R.B., 2009. Antagonism test of 
fungal pathogen of Phytophthora infestans causes late blight and potato tuber using Trichoderma spp. local isolates. Bioma. 11(1), 24-32.

Rodriguez, R.J., White, J.F., Arnold, A.E., Redman, R.S., 2009. Fungal endophytes: Diversity and functional roles. New Phytol. 182, 314-330.

Sayledra, A., Firia, D., 2013. Entophytic fungi roots of corn potency as plant growth poromoting. J. Ilmu Pertan. Perikanan. 2(2), 135-140.

Spaepen, S., Jos, V., Roseline, R., 2007. Indole-3 Acetic Acid in Mirovial and Microorganism Plant Signaling. Departemen of Microbial and Plant
Genetics, Belgium.

Sutoyo, 2009. The Effect of Aspergillus niger Root Endopyte Inoculation and Phosphate Treatment on Growth of Upland Rice (Oryza sativa) and Corn (Zea mays). [Thesis], IPB Graduate School, Bogor.

Waller, F., Achatz, B., Baltruschat, H., Fodor, J., Becker, K., Fischer, M., Heier, T., Huckelhoven, R., Neumann, C., von Wettstein, D., 2005. The endophytic fungus Piriformospora indica reprograms barley to salt-stress tolerance, disease resistance, and higher yield. Proc. Nat. Acad. Sci. (USA). 102, 13386-13391.

\section{How to cite this article:}

Syamsia, Idhan. A., Kadir, M., 2016. The potency of entophytic fungal isolates from local aromatic rice as plant growth promoting agents. Int. J. Curr. Res. Biosci. Plant Biol. 4(1), 1-5.

doi: http://dx.doi.org/10.20546/ijcrbp.2017.401.001 